\title{
A new hybrid technique of cuckoo search and harmony search for solving non-smooth optimal power flow framework
}

\author{
Aboubakr Khelifi*, Saliha Chettih, Bachir Bentouati \\ University of Ammar Teledji Laghouat, Electrical Engineering Department, Laghouat, Algeria
}

Corresponding Author Email: khelifi@lagh-univ.dz

https://doi.org/10.18280/ama_b.610402

Received: 15 March 2018

Accepted: 5 June 2018

\section{Keywords:}

Cuckoo Search, harmony search, optimal power flow, emission, constraints

\begin{abstract}
In order to improve the search capability of the existing Cuckoo Search (CS) algorithm, an enhanced robust technique is proposed in this paper, called hybrid Cuckoo Search and Harmony Search (CSHS). In CSHS technique, HS incorporates the mutation operator into the Cuckoo Search technique. The proposed technique is applied to solve the highly nonlinear and non-convex optimal power flow (OPF) problem. In this paper, OPF is mathematically formulated as nonlinear multi-objective optimization problem. The developed formulation minimizes simultaneously the conflicting objectives of fuel cost, valve-point effect, emission reduction, voltage profile improvement and voltage stability enhancement subject to system equality and inequality constraints. OPF problem is solved using the proposed CSHS algorithm and tested on standard IEEE 30-bus and IEEE 57-bus with different case studies. The results obtained are compared with the reported literature. The results demonstrate that the proposed algorithm outperforms the original CS and HS and other algorithms available in the literature.
\end{abstract}

\section{INTRODUCTION}

The Optimal Power Flow (OPF) is a significant appliance for planning and operation studies in the power system operator. OPF is a widely non-linear and non-convex optimization problem, and this is more difficulty in practical applications in the large number's presence of discrete variables. The goal of OPF is to provide the optimal settings of the power system by improving objective function while meeting the equality and inequality constraints [1], then this problem has been addressed by several researchers. The objective functions, such as the minimization of total fuel cost, improvement of voltage stability index and reduction of real power loss are considered individually in the literature for this study [2]. The problem of power flow is one of the fundamental problems in which the load and the powers of generator are given or corrected. The OPF has a long history in its development, and it was primary introduced by Carpentier in 1962 [1] and the next investigations on OPF in [2]. However, it took a long time to turn into an effective technique that could be applied in daily use. The actual interest for OPF is focused on its capability to solve for the optimal solution that has considered the security of the system. The optimal power flow has been applied to regulate the active power outputs and voltages of the generator, transformer tap settings, shunt reactors/capacitors and other controllable variables to minimize the generator fuel cost, network active power loss, voltage stability index, while keeping all the load bus voltages, generator reactive power outputs, network power flows, and all other state variables in the power system within their secure and operational bounds. In its most common problem formulation, the OPF is a nonconvex, static, large-scale optimization problem with both continuous and discrete control variables [3]. Even in the absence of non-convex generator operating cost functions, prohibited operating zones (POZs) of generating units, and discrete control variables, the OPF problem is a non-convex because of the existence of the non-linear alternating current power flow equality constraints. The existence of discrete control variables, such as transformer tap positions, switchable shunt devices, phase shifters, further complicates the formulation and solution of the problem [4].

Different conventional optimization methods have been used to solve the OPF problem. These involve newton methods [5], interior point method [6], and linear programming [7], a comprehensive survey of different conventional optimization techniques used to solve OPF problems was presented. Nevertheless, in practice, conventional techniques suffer from some weakness. Some of its shortcomings through other things are: First, they do not assure to find the global optimum, second, conventional techniques involve complex computations with a long time, and they do not suitable for discrete variables [8].

During the last little decades, a lot powerful metaheuristics were developed. Several of them have been implemented to the OPF problem with very successfully. various of the modern implementations of meta-heuristics for the OPF problem are: Particle Swarm Optimization (PSO) [9,10], Hopfield Neural Network (HNN) [11], Elephant Herding Optimization (EHO) [12], Moth Flam Optimizer (MFO) [13], Biogeography-Based Optimization (BBO) [14], Differential Search Algorithm (DSA) [15], Multi-Verse Optimizer (MVO) [16], and Krill Herd Algorithm (KHA) [17]. Though, because of changing objectives while solving OPF problems, no algorithm is the greatest one to solve all the OPF problems. Consequently, there is still a need for a novel algorithm, which can effectively solve the most of OPF problems. In addition, enhanced efficiency is often carried 
out by hybridizing the technique and deterministic optimization methods. Enhancing the searching capability of the optimal solutions is the goal of technique hybridization.

The Cuckoo Search (CS) technique is a perfectly new optimization algorithm, which is designed based on the Lévy flight and brood parasitic behavior of certain cuckoo species [18]. Further, CS can yield optimum solution but the searching operation using levy flight cannot be assured. So as to overcome the problem, Harmony Search (HS) [19] can be one of the method to be incorporated with cuckoo search. HS can give a mutation operator to the Cuckoo Search technique. Thus, the exploitation ability of the solution will be best. By using the characteristics of CS and HS, this paper suggests a hybrid (CSHS), The effectiveness of this technique is utilized to keep away from local optima and get a worldwide ideal solution, in addition, less computational time to achieve the ideal solution, local minima evasion, and speeder convergence, which make them adequate for viable applications for solving various constrained optimization problems. The goal of this paper is to develop an enhanced CS called CSHS to solve OPF problem. In order to justify the development of the CSHS, its efficiencies are compared to CS, HS and other well-known optimization techniques. Two exam systems networks IEEE 30-bus and IEEE 57-bus test systems are considered.

The remainder of paper is organized in the following way: The next partout lines the formulation of the OPF problem; meanwhile, section 3 describes the algebraic equation of CSHS. Section 4 displays the results of simulation and discussion. Finally the conclusion of this work is in section 5.

\section{OPTIMAL POWER FLOW (OPF)}

The OPF is a power flow problem that provides the optimal settings of the control variables for specific settings of load by means of reducing a predefined objective function such as the cost of real power generation or transmission losses. OPF takes into account the operating limits of the system and it can be mathematically formulated as a nonlinear constrained optimization problem as follows:

Minimize: $J(x, u)$

$$
g(x, u) \leq 0
$$

Subject to:

$h(x, u)=0$

where $J(x, u)$, objective function; $h(x, u)$, set of equality constraints; $g(x, u)$, set of inequality constraints; u vector of control variables; $\mathrm{x}$, vector of state variables; The control variables $\mathrm{u}$ and the state variables $\mathrm{x}$ of the OPF problem are explained in relations (2) and (3), respectively.

Control variables:

These are the set of variables that can be regulated to satisfy the load flow equations [20]. The set of control variables in the mathematical formulation of the OPF problem are:

$P G$ : is the $i$-th active power bus generator (except swing generator). $V G$ : is the voltage magnitude at $i$-th $\mathrm{PV}$ bus (generator bus). $T$ : is a transformer tap setting.

$Q C$ : is shunt VAR compensation.
The control variables $\boldsymbol{U}$ can be formulated as:

$u=\left[P_{G_{2}} \ldots P_{G_{N G}}, V_{G_{1}} \ldots V_{G_{N G}}, Q_{C_{1}} \ldots Q_{C_{N C}}, T_{1} \ldots T_{N T}\right]$

where $N C, N T$ and $N G$ are the number of $V A R$ compensators, the number of regulating transformers and the number of generators respectively.

State variables:

These are the set of variables that report any unique state of the system [20]. The set of state variables for mathematically formulated the OPF problem as follow:

$P G 1$ : is the generator active power at slack (or swing) bus. $V L$ : is the bus voltage of $p$-th load bus (PQ bus).

$Q G$ : reactive power generation of all generator units.

$S L$ : transmission line loading (or line flow)

The state variables $\boldsymbol{X}$ can be formulated as:

$x=\left[P_{G_{1}}, V_{L_{1}} \ldots V_{L_{N L}}, Q_{G_{1}} \ldots Q_{G_{N G}}, S_{l_{1}} \ldots S_{l_{n l}}\right]$

where, $N L$, and $n l$ are the number of load buses and the number of transmission lines, respectively.

Constraints:

OPF constraints can be classified into equality and inequality constraints, as explained in the next sections.

Equality constraints

The equality constraints that express the typical nonlinear power flow equations that control the power system, presented as follows.

a) Real power constraints:

$$
P_{G_{i}}-P_{D_{i}}-V_{i} \sum_{j=1}^{N B} V_{j}\left[G_{i j} \cos \left(\delta_{i j}\right)+B_{i j} \sin \left(\delta_{i j}\right)\right]=0
$$

Reactive power constraints:

$$
Q_{G_{i}}-Q_{D_{i}}-V_{i} \sum_{j=1}^{N B} V_{j}\left[G_{i j} \sin \left(\delta_{i j}\right)+B_{i j} \cos \left(\delta_{i j}\right)\right]=0
$$

where NB is the number of buses, $P_{D}$ and $Q_{D}$ are active and reactive load demands, respectively, $\delta_{i j}=\delta_{i}-\delta_{j}$ is the difference in voltage angles between bus $i$ and bus $j G_{i j}$ is the transfer conductance and $B_{i j}$ is the susceptance between bus $i$ and bus $j$, respectively.

Inequality constraints:

The Inequality constraints that reflect operational of the system and the system's physical limits presented as follows.

Generator constraints. For all generators comprising the slack: voltage, active and reactive outputs shall to be limited by their minimum and maximum limits as follows:

$$
\begin{aligned}
& V_{G_{i}}^{\min } \leq V_{G_{i}} \leq V_{G_{i}}^{\max } \forall i \in N G \\
& P_{G_{i}}^{\min } \leq P_{G_{i}} \leq P_{G_{i}}^{\max } \forall i \in N G \\
& Q_{G_{i}}^{\min } \leq Q_{G_{i}} \leq Q_{G_{i}}^{\max } \forall i \in N G
\end{aligned}
$$


Transformer constraints. Transformer tap settings must be limited within their specified minimum and maximum limits as follows:

$T_{j}^{\min } \leq T_{j} \leq T_{j}^{\max } \forall j \in N T$

Shunt VAR compensator constraints. Shunt VAR compensators have to be limited by their lower and upper limits as follows:

$Q_{C_{k}}^{\min } \leq Q_{C_{k}} \leq Q_{C_{k}}^{\max } \forall k \in N C$

Security constraints:

These comprise the constraints of voltage magnitude at load buses and transmission line loadings. Voltage of each load bus has to be limited within its minimum and maximum operating limits. Line flow through each transmission line must be limited by its capacity limits. These constraints can be expressed as given follows:

$V_{L_{p}}^{\min } \leq V_{L_{p}} \leq V_{L_{p}}^{\max } \forall p \in N L$

$S_{l_{q}} \leq S_{l_{q}}^{\max } \forall q \in n l$

where $V_{L_{p}}^{\min }$ and $V_{L_{p}}^{\max }$ represents lowest and upper load voltage of ith unit, ${ }^{S_{l_{q}}}$ represents apparent power flow of ith branch $S_{l_{q}}^{\max }$ represents maximum apparent power flow limit of $i$ th branch.

\section{HARMONY SEARCH}

In 2001, Geem et al. first proposed the harmony search (HS) algorithm [19], the fundamental HS technique involves the following operators: the harmony memory (HM) [see Eq. (13)], the harmony memory size (HMS), the harmony memory consideration rate (HMCR), the pitch adjustment rate (PAR) and the pitch adjustment bandwidth ( $b w)$.

$$
H M=\left[\begin{array}{llll|l}
x_{1}^{1} & x_{2}^{1} & \ldots & x_{D}^{1} & \text { fitness }\left(x^{1}\right) \\
x_{1}^{2} & x_{2}^{2} & \ldots & x_{D}^{2} & \text { fitness }\left(x^{2}\right) \\
\vdots & \vdots & \ldots & \vdots & \vdots \\
x_{1}^{H M S} & x_{2}^{H M S} & \ldots & x_{D}^{H M S} & \text { fitness }\left(x^{H M S}\right)
\end{array}\right]
$$

Within HS, there are three elements: use of harmony memory, pitch adjusting, and randomization. In the process of HS optimization, the value of each decision variable in $\mathrm{HM}$ can be specified by one of the previously mentioned three rules.

The first section is important in the entire HS process. This can assure that the preferable harmonies cannot be varied and make the HM always stay the preferable status. HMCR $\in[0$, 1] must be cautiously adjusted with the goal of using this memory more successfully. If it is nears 1 (very high), almost whole the harmonies in them can be completely exploited, but the HS algorithm cannot perform a global search, leading to possible wrong solutions. On the other hand, if it is too small (even 0), HS uses only a few preferable harmonies, which may result to slowly finding the preferable solutions. Here, usually, HMCR $=0.7-0.95$. For the second section, although the pitch can be lightly adjusted in the linear form or nonlinear theoretically, a linear adjustment is selection in most cases. The pitch is modernized as follows:

$$
x_{\text {new }}=x_{\text {old }}+b w(2 \delta-1)
$$

where $\delta$ is a number's random in $[0,1], b w$ is the band width. $x_{\text {old }}$ And $x_{\text {new }}$ are the actual and novel pitches, respectively.

Pitch adjustment has the likeness with the mutation operator in evolutionary techniques. Likewise, the PAR is also cautiously adjusted in order to implement HS in the best way. If PAR gets closer to 1, the harmony in HM will switch even at the finale of the HS operation, and HS is therefore difficult to converge on the best solutions. Conversely, if it is too low, then a slight change will be made for harmonies in HS and HM might converge prematurely. Hence, we use PAR $=0.1-0.5$ for generality cases. The third section is basically a random process with the goal of adding harmony diversity. The random operation makes the HS explore the entire search space excellently and this has a greater prospect of finding the final optimal solutions.

\section{CUCKOO SEARCH}

By simplifying and perfecting the parasitic the conduct of the brood of cuckoos individuals in incorporation with Lévy flight, CS is proposed which is a new technique of metaheuristic research [18] to solve optimization problems.

In the state of $\mathrm{CS}$, how a cuckoo individual moves to the following position is entirely specified by Lévy flights.

To use cuckoo brood the conduct to optimization problems, Yang and Dib are ideal for the brood parasitic the conduct of some cuckoo, the following three rules have been developed forward.

1. In the cuckoo population, every cuckoo puts an egg at a nest chosen at random.

2. Great -quality nests will not be changed, and this can assure the cuckoo population that involves the superior solutions, not worse than previously at least.

3. The number of nests is not changed and the egg laid by a cuckoo is found by the host bird with a possibility pa $\in[0$, $1]$.

In the easy form, every nest only repays only to one an egg. As a result, the CS technique can be simply extended to address multi-objective optimization problems in which every nest comprises more than one egg / solution. In our current study, we only consider that every nest has just an egg. So, in our study, we do not determine the difference between the nest, egg, and solution. CS technique can achieve a perfect balance between the local random walk and the global random walk by utilizing a $p a$ switch parameter. The local one can be expressed as [18]: 
$X_{i}^{t+1}=X_{i}^{t}+\beta_{s} \otimes H\left(p_{a}-\varepsilon\right) \otimes\left(X_{j}^{t}-X_{k}^{t}\right)$

Where $X_{j}^{t}$ and $X_{k}^{t}$ are two diverse solutions randomly chosen, $\mathrm{H}(\mathrm{u})$ is a Heaviside function, $\varepsilon$ is a number's random, and $\mathrm{s}$ is the step size, For the global random walk, it is incorporated with Lévy flights given as follows:

$X_{i}^{t+1}=X_{i}^{t}+\beta L(s, \lambda), L(s, \lambda)=\frac{\lambda \Gamma(\lambda) \sin \left(\frac{\pi \lambda}{2}\right)}{\pi} \frac{1}{s^{1}+\lambda},\left(s, s_{0} \succ 0\right)$

Here $\beta>0$ is the scaling factor of the step size concerning to the scales of the interest problem.

\section{HYBRID HARMONY SEARCH AND CUCKOO SEARCH}

Based on the introduction of CS and HS in earlier section, the detailed characterize of the suggested cuckoo search with harmony search (HS/CS) will be presented in this section.

In general, the standard CS technique explores the search space well and has a quick speed to find the optimal global value, but it takes exploits of solutions badly because of the moves or sometimes large steps. Furthermore, standard harmony search is well able to exploit solutions by carefully adjusting the HMCR and PAR. In the display work, by combination of HS and CS, a hybrid meta-heuristic technique, so-called Cuckoo Search/harmony Search (CS/HS) is thus suggested for the goal of optimizing benchmark functions. In $\mathrm{CS} / \mathrm{HS}$ technique, the improvisation of harmony in HS is inserting into cuckoo search as operator of mutation. In this process, this technique can explore the modern search space by hybrid CS operator and exploit population with HS, and thus, the benefits of the CS and HS can be fully utilized.

The basic idea of the HS/CS technique is the provided of the hybrid HS mutation operator. In this way, first introduced in the current work, a major improvement is made to add a mutation operator to the CS including two minor improvements.

The first improvement is the addition of the pitch adjustment process in the HS, which can be considered a mutation operator in order to augment the diversity of the population. In the exploitation phase, once an individual is selected among the best current individuals, a new Cuckoo individual is created globally using Lévy flights. After that, we adjust each element in $x_{i}$ using HS. When $\xi$ is greater than HMCR, i.e., $\xi_{1} \geq \mathrm{HMCR}$, the component $\mathrm{j}$ is updated randomly; whereas when $\xi_{1}<\mathrm{HMCR}$, we update component $\mathrm{j}$ according to $x^{*}$, furthermore, pitch adjustment process in HS which can be considered as a mutation operator is applied to update the component $\mathrm{j}$ when $\xi_{2}<\mathrm{PAR}$ in a purpose to add diversity of the population, as described in equation (14), where $\xi_{1}$ and $\xi_{2}$ are two random numbers distributed uniformly in $[0,1], x^{*}$ is the global preferable solution in the current generation. By means of different experiments, it was found that HMCR is specific to 0.9 and PAR to 0.1 which can produce optimal solutions.

The else improvement is to add of elitist scheme to into the HS/CS.As with else optimization techniques, an improved elitism scheme is combined into the HS/CS algorithm to retain the preferable individuals in the cuckoo population.
According to the above detailing, the harmony search/cuckoo search (HS/CS) can be found in the corresponding flowchart appears in Figure 1.

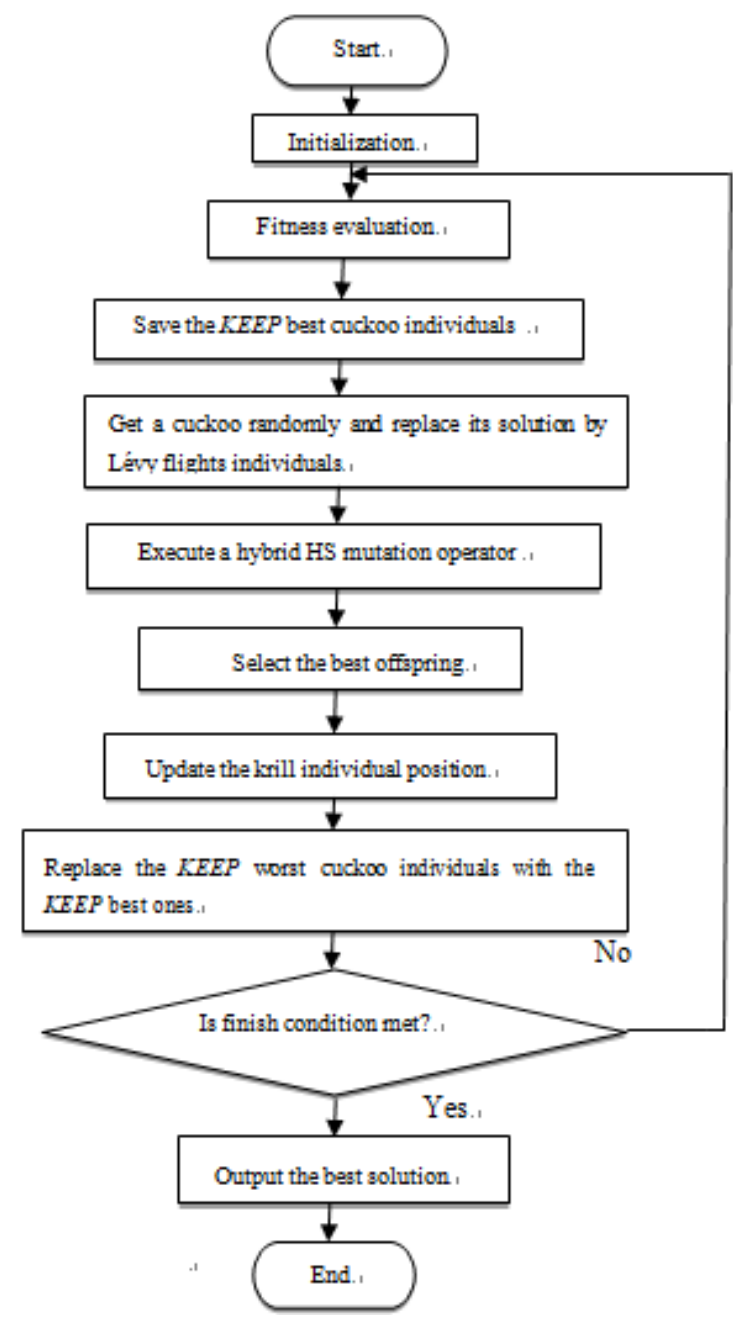

Figure 1. The flowchart of Hybrid CSHS algorithm

\section{APPLICATION AND RESULTS}

The CSHS has been using to solve the OPF problem for two exam systems and for many cases with various objective functions. The considered power systems networks are: the IEEE 30-bus and IEEE 57-bus test system. The advanced software program is written in MATLAB computing environment and used on a $2.20 \mathrm{GHz}$ i7 personal computer. In our study the CSHS population size or number of stars is selection to be 50 .

\subsection{IEEE 30-bus test system}

In order to illustrate the performance of the proposed CSHS method, it has been examined first on the standard IEEE 30-bus test system. The standard IEEE 30-bus system selection in this paper has the next characteristics: 6generators at buses 1, 2, 5, 8, 11 and 13, 4-transformers with off-nominal tap ratio at lines $11,12,15$ and 36, 9- shunt VAR compensation buses at buses 10,12, 15, 17, 20, 21, 23, 24 and 29. In addition, line data, bus data, generator data, and lower and upper restriction for control variables are presented in [21]. For this first exam system, six various cases have 
been studied with various objectives and all the obtained results are outlined in Table 1, 3 and 5. The first column of this table appears the optimal control settings found where:

- PG1 through PG6 and VG1 through VG6 represent the powers and the voltages of generator 1 through generator 6 .

- T11, T12, T15 and T36 are the tap settings of transforms involved between lines $11,12,15$ and 36 .

- QC10, QC12, QC15, QC17, QC20, QC21, QC23, QC24 and QC29 represent the shunt VAR compensations connected to buses 10,12, 15, 17, 20, 21, 23, 24 and 29.moreover, fuel cost $(\$ / h)$, active power losses $(M W)$, reactive power losses (MVar), voltage deviation and Lmax represent the total fuel cost of the system, the total active transmission losses, the deviation of load voltages and the index of stability, respectively. More description about these results will be presented in the next sections.

Case 1: Minimization of generation fuel cost

The first case studied in this article is the basic case of minimizing the cost generation fuel expressed by a quadratic function. Therefore, the objective function of this case is:

$$
J=\sum_{i=1}^{N G} f_{i}(\$ / h)
$$

where $f i$ is the fuel cost of the ith generator. Usually, the OPF generation fuel cost curve is formulated by a quadratic function. Hence, $f i$ can be formulated as follows [16]:

$f_{i}=\left(a_{i}+b_{i} P_{G_{i}}+c_{i} P_{G_{i}}^{2}\right)$

where $a_{i}, b_{i}$ and $c_{i}$ are the element, the linear and the quadratic cost coefficients of the ith generator, respectively. The values of these coefficients are presented in [21].

Figure 2 appears the trend of total fuel cost over iterations. It seems that the proposed technique has good convergence characteristics. The optimal settings of control variables are presented in table 1 . The total fuel cost obtained by the suggested CSHS technique is $(798.9166 \$ / \mathrm{h})$. Compared to the original CS, HS the total fuel cost is significantly decreased. Using the identical conditions (limits of control variables, initial conditions, and system data), the results obtained in Case 1 apply the CSHS technique are compared to other methods described in the literature as appears in Table 2. There is some proof, that the suggested technique outperforms several methods used to solve the OPF problem by decreasing of generation fuel cost. For instance, the results obtained by the CSHS are better than the ones obtained the CS and HS methods.

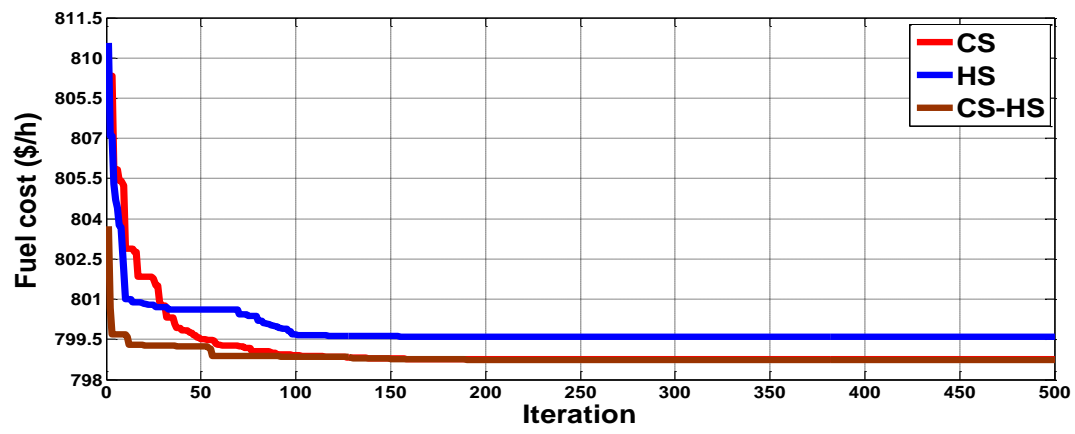

Figure 2. Objective function curve for CASE 1

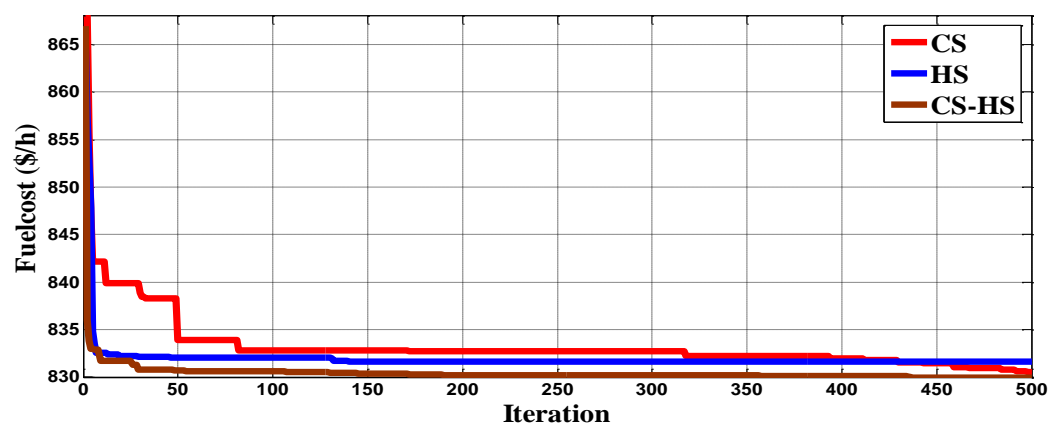

Figure 3. Objective function curve for CASE 2

Table 1. Optimum control variables for case 1 and case 2

\begin{tabular}{|c|c|c|c|c|c|c|}
\hline \multirow[b]{2}{*}{ Control variable } & \multicolumn{2}{|c|}{ Case1 } & \multirow[b]{2}{*}{$\mathrm{HS}$} & \multicolumn{3}{|c|}{ Case2 } \\
\hline & CS-HS & $\mathrm{CS}$ & & CS-HS & $\mathrm{CS}$ & $\mathrm{HS}$ \\
\hline $\mathrm{P}_{\mathrm{G} 1}(\mathrm{MW})$ & 177.1113 & 177.1178 & 178.1042 & 200.0281 & 200.0828 & \\
\hline 200.0000 & & & & & & \\
\hline $\begin{array}{l}\mathrm{P}_{\mathrm{G} 2}(\mathrm{MW}) \\
43.5433\end{array}$ & 48.6899 & 48.6915 & 49.1159 & 42.8209 & 41.8634 & \\
\hline $\begin{array}{l}\mathrm{P}_{\mathrm{G} 5}(\mathrm{MW}) \\
18.6056\end{array}$ & 21.303 & 21.3039 & 21.3845 & 18.8234 & 18.4909 & \\
\hline $\mathrm{P}_{\mathrm{G} 8}(\mathrm{MW})$ & 21.0241 & 21.0311 & 21.6787 & 10.0000 & 11.2835 & \\
\hline
\end{tabular}




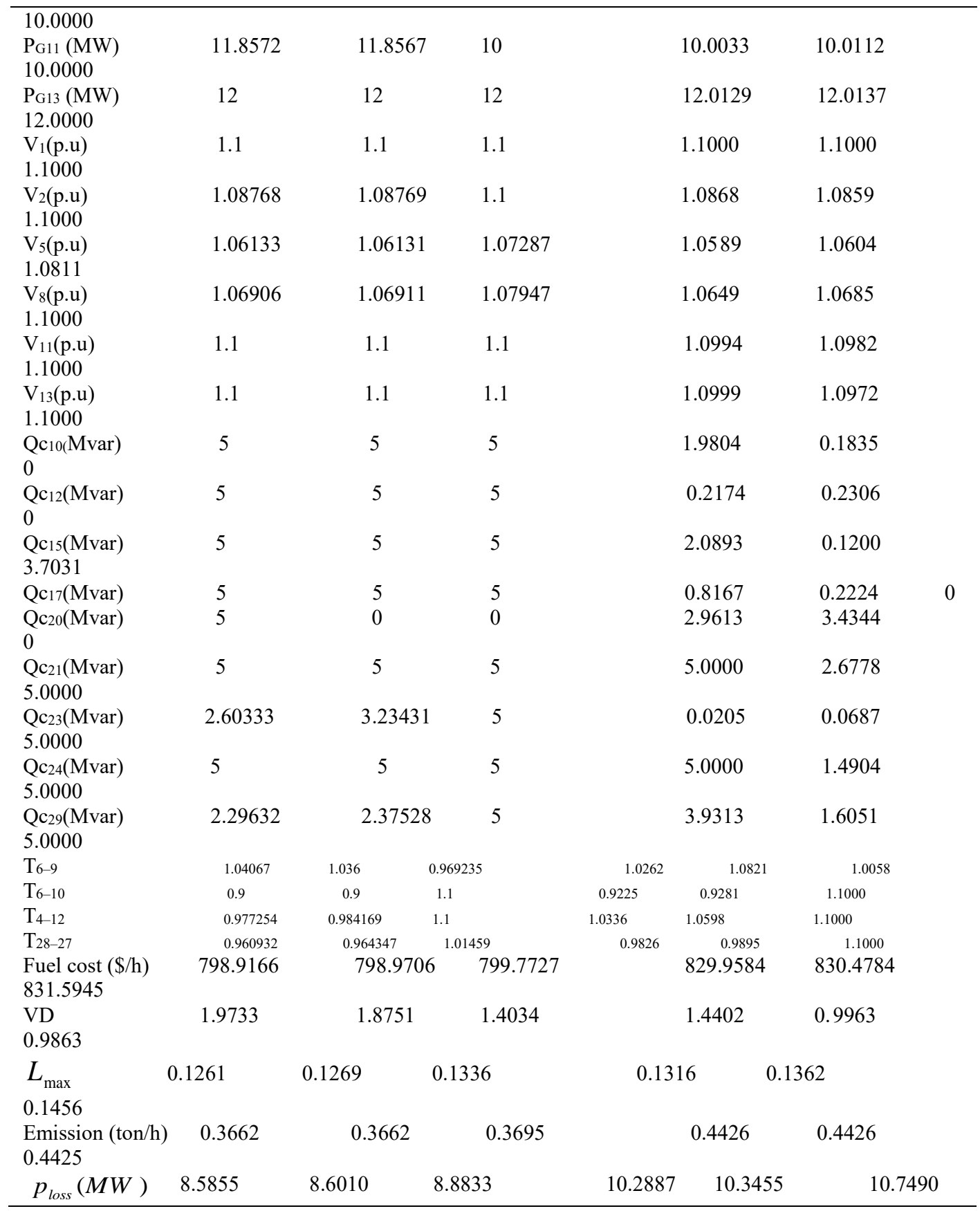

Case 2: Minimization of fuel cost considering valve point effect

So as to have a realistic and greater effective modeling of generator cost functions, the valve point-effect must be considered. The generating units with multi-valve steam turbines display a major variation in the fuel-cost functions and output a ripple-like effect. So as to considered the valvepoint effect of generating units, a modeled as a sinusoidal term is added to the cost function [24]. Thus, the objective function can be formulated as follow:

$f(x, u)=\sum_{i=1}^{N G}\left(a_{i}+b_{i} P_{i}+c_{i} P_{i}^{2}\right)+\mid d_{i} \times\left(e_{i} \times\left(P_{g i}^{\min }-P_{g i}\right) \mid\right.$

where, $d_{i}$ and $e_{i}$ are the coefficients that show the valve-point loading effect.

In this case to arrive at a rise in cost than in case 1 with conclusive value being $829.9584 \$ / \mathrm{h}$, obtained by CSHS. The optimal control variables obtained are shown in Table1, output outcome of method used in our study are better than most of the results revealed in past literatures on the problem of OPF.

Table 2. Comparison of results for case 1 and case 2

\begin{tabular}{cccc}
\hline \multicolumn{2}{c}{ Case 1 } & \multicolumn{2}{c}{ Case 2 } \\
\hline Algorithms & $\begin{array}{c}\text { Fuel } \\
\text { cost }(\$ / \mathrm{h})\end{array}$ & Algorithms & Fuel cost $(\$ / \mathrm{h})$ \\
\hline CS-HS & 798.9166 & CS-HS & 829.9584 \\
CS & 798.9706 & CS & 830.4784 \\
HS & 799.7727 & HS & 831.5945 \\
DE [21] & 799.289 & BSA [20] & 830.7779 \\
SOS[22] & 801.5733 & ICBO [25] & 830.4531 \\
MSFLA[23] & 802.287 & APFPA [26] & 830.4065 \\
HSFLA- & 801.79 & & \\
SA[24] & & & \\
\hline
\end{tabular}

Case 3: Minimization of fuel cost and voltage deviation

Bus voltage is one of the most significant and considerable security and service quality indices [21]. Reducing only the total cost in the OPF problem as in Case 1 may result in a suitable solution, but voltage profile may not be reasonable. 
Consequently, this case purposes at minimizing fuel cost with a improve voltage profile by considering a dual objective function. The voltage profile is optimized by reducing the load bus voltage deviation (VD) from 1.0 p.u, the objective function in this case can be formulated as follows:

$$
J=J_{\text {cost }}+w J_{\text {voltageDeviation }}
$$

where $\mathrm{w}$ is an appropriate weighting factor, to be chosen by the user to accord a weight to each of the two expressions of the objective function. In this case $w$ is selection as 100 .

$J_{\text {cost }}$ and $J_{\text {VoltageDeviation }}$ are presented as follows:

$$
J_{\cos t}=\sum_{i=1}^{N G} f_{i}
$$

$$
J_{\text {voltageDeviation }}=\sum_{k=1}^{N L}\left|V_{i}-1\right|
$$

The CSHS technique has been utilized to search for the optimal solution of the problem. The variations in the fuel cost and voltage deviation through the iterations are outlined in Fig.4a and Fig.4b. The optimal settings of the control variables are presented in table 3. Apply CSHS the fuel cost and the voltage deviation yielded are $(803.5208 \$ / \mathrm{h})$ and (0.0991p.u), respectively. The voltage profile obtained by CSHS is compared with other algorithms as appears in table 4. It is clear that the voltage profile is the least among all other comparable methods. It is decreased from 1.9733 p.u. In the case 1 to $0.0991 \mathrm{p}$.u in case 3 , hence, in case 3 , the fuel cost is slightly augmented by $0.57 \%$ compared to case 1 .

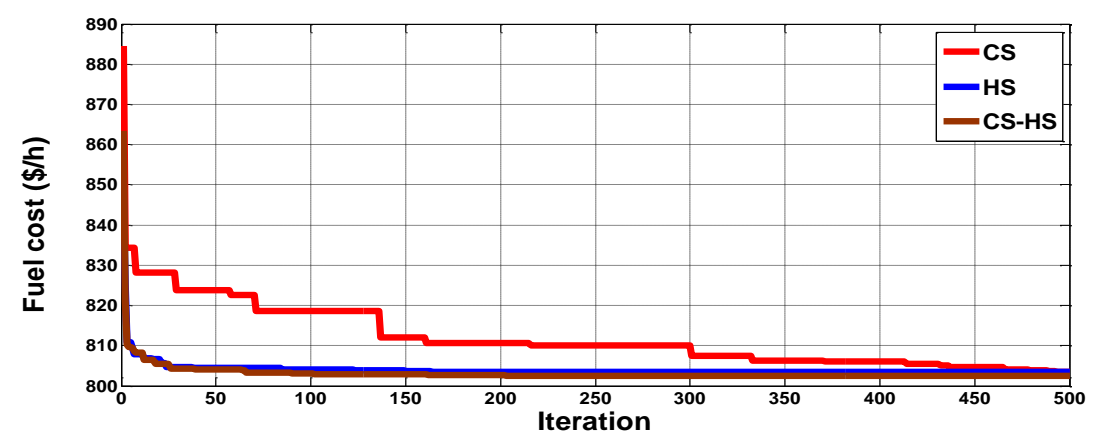

Figure 4a. Objective function curve for CASE3

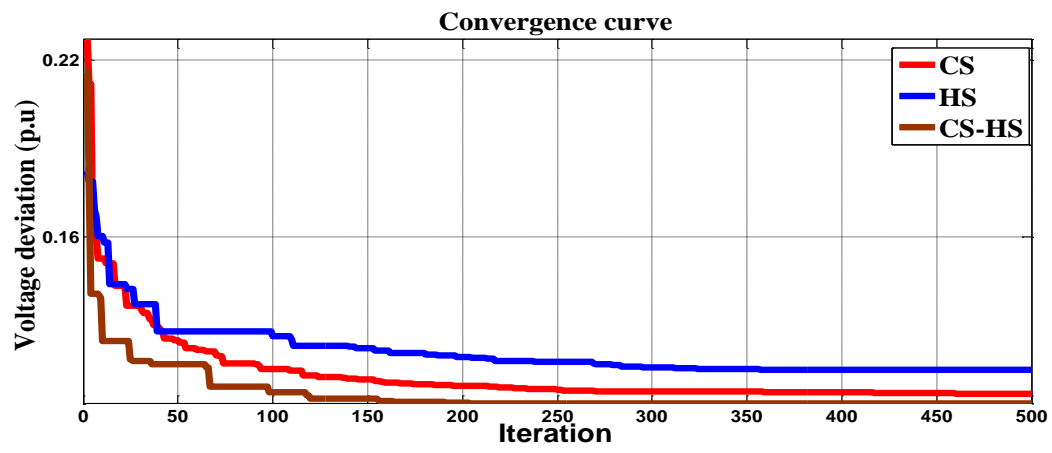

\begin{tabular}{|c|c|c|c|c|c|c|}
\hline \multirow[b]{2}{*}{ Control variable } & \multicolumn{2}{|c|}{ Case3 } & \multirow[b]{2}{*}{ HS } & \multicolumn{2}{|c|}{ Case4 } & \multirow[b]{2}{*}{ HS } \\
\hline & CS-HS & $\mathrm{CS}$ & & CS-HS & $\mathrm{CS}$ & \\
\hline $\mathrm{P}_{\mathrm{G} 1}(\mathrm{MW})$ & 176.1521 & 177.8590 & 176.5090 & 178.0124 & 177.2886 & 177.8314 \\
\hline $\mathrm{P}_{\mathrm{G} 2}(\mathrm{MW})$ & 48.6077 & 49.0616 & 48.9845 & 49.4689 & 50.1364 & 49.0497 \\
\hline $\mathrm{P}_{\mathrm{G} 5}(\mathrm{MW})$ & 21.6759 & 21.6616 & 21.5998 & 21.2303 & 20.9317 & 21.4515 \\
\hline $\mathrm{P}_{\mathrm{G} 8}(\mathrm{MW})$ & 22.5226 & 22.9236 & 22.3333 & 19.4564 & 18.0767 & 22.1245 \\
\hline $\mathrm{P}_{\mathrm{G} 11}(\mathrm{MW})$ & 12.2148 & 10 & 11.9979 & 11.7191 & 12.5048 & 10.0000 \\
\hline $\mathrm{P}_{\mathrm{G} 13}(\mathrm{MW})$ & 12 & 12 & 12 & 12.3024 & 13.3872 & 12.0000 \\
\hline $\mathrm{V}_{1}(\mathrm{p} . \mathrm{u})$ & 1.03871 & 1.05487 & 1.04718 & 1.1000 & 1.1000 & 1.1000 \\
\hline $\mathrm{V}_{2}$ (p.u) & 1.02104 & 1.036 & 1.0312 & 1.0886 & 1.0905 & 1.1000 \\
\hline $\mathrm{V}_{5}$ (p.u) & 1.00946 & 1.01811 & 1.01833 & 1.0676 & 1.0667 & 1.1000 \\
\hline $\mathrm{V}_{8}(\mathrm{p} . \mathrm{u})$ & 0.99976 & 1.00864 & 1.01295 & 1.0749 & 1.0727 & 1.1 \\
\hline $\mathrm{V}_{11}$ (p.u) & 1.07605 & 0.9969 & 0.95 & 1.1000 & 1.1000 & 1.1 \\
\hline $\mathrm{V}_{13}$ (p.u) & 0.99678 & 0.96439 & 0.98414 & 1.1000 & 1.1000 & 1.1 \\
\hline $\mathrm{Qc}_{10}$ (Mvar) & 4.9997 & 0 & 5 & 1.9688 & 0.5394 & 5 \\
\hline $\mathrm{Qc}_{12}$ (Mvar) & 0 & 0 & 5 & 0.4147 & 1.3942 & 0 \\
\hline $\mathrm{Qc}_{15}$ (Mvar) & 5 & 5 & 5 & 0 & 0.1355 & 5.0000 \\
\hline $\mathrm{Qc}_{17}$ (Mvar) & 0 & 3.65345 & 5 & 2.6176 & 0.5193 & 5.0000 \\
\hline
\end{tabular}

Figure 4b. Objective function curve for CASE3

Table 3. Optimum control variables for case 3 and case 4 


\begin{tabular}{lllllll}
\hline $\mathrm{Qc}_{20}$ (Mvar) & 5 & 4.99998 & 5 & 3.4887 & 0.0944 & 0 \\
$\mathrm{Qc}_{21}$ (Mvar) & 5 & 5 & 5 & 4.3462 & 0.1221 & 0 \\
$\mathrm{Qc}_{23}$ (Mvar) & 5 & 5 & 5 & 1.7656 & 3.3164 & 4.3684 \\
$\mathrm{Qc}_{24}$ (Mvar) & 5 & 5 & 0 & 5.0000 & 0.0099 & 5.0000 \\
$\mathrm{Qc}_{29}$ (Mvar) & 2.49152 & 5 & 1.76278 & 0.2188 & 0.3625 & 2.1684 \\
$\mathrm{~T}_{6-9}$ & 1.1 & 1.00336 & 0.96716 & 1.0400 & 1.0075 & 1.1000 \\
$\mathrm{~T}_{6-10}$ & 0.9 & 0.9 & 0.9 & 0.9192 & 0.9043 & 0.9000 \\
$\mathrm{~T}_{4-12}$ & 0.95347 & 0.9 & 0.94311 & 0.9835 & 1.0060 & 0.9996 \\
$\mathrm{~T}_{28-27}$ & 0.96762 & 0.97936 & 0.95791 & 0.9416 & 0.9313 & 0.9723 \\
Fuel cost $(\$ / \mathrm{h})$ & 803.5208 & 804.2983 & 804.2596 & 799.3251 & 800.0275 & 800.4916 \\
$\mathrm{VD}$ & 0.0991 & 0.1040 & 0.1122 & 1.7688 & 1.6361 & 1.9221 \\
$L_{\text {max }}$ & 0.1487 & 0.1493 & 0.1482 & 0.1251 & 0.1254 & 0.1249 \\
Emission (ton/h) & 0.3632 & 0.3686 & 0.3643 & 0.3689 & 0.3666 & 0.3688 \\
$p_{\text {loss }}(M W)$ & 9.7731 & 10.1058 & 10.0245 & 8.7895 & 8.9254 & 9.0572 \\
\hline
\end{tabular}

Table 4. Comparison of results for case 3 and case 4

\begin{tabular}{|c|c|c|c|c|c|}
\hline \multicolumn{3}{|c|}{ Case 3} & \multicolumn{3}{|c|}{ Case 4} \\
\hline Algorithms & $\begin{array}{c}\text { Fuel } \\
\operatorname{cost}(\$ / \mathrm{h})\end{array}$ & VD(p.u) & Algorithms & Fuel $\operatorname{cost}(\$ / \mathrm{h})$ & $L_{\max }$ \\
\hline CS-HS & 803.5208 & 0.0991 & CS-HS & 799.3251 & 0.1251 \\
\hline $\mathrm{CS}$ & 804.2983 & 0.1040 & $\mathrm{CS}$ & 800.0275 & 0.1254 \\
\hline HS & 804.2596 & 0.1122 & HS & 800.4916 & 0.1249 \\
\hline BSA [20] & 803.4294 & 0.1147 & $\begin{array}{l}\text { ARCBBO } \\
{[27]}\end{array}$ & 801.8076 & 0.1369 \\
\hline $\mathrm{DE}[21]$ & 805.2620 & 0.1357 & BSA [20] & 800.3340 & 0.1259 \\
\hline BBO [14] & 804.9980 & 0.102 & $\mathrm{ABC}[28]$ & 801.6650 & 0.1379 \\
\hline
\end{tabular}

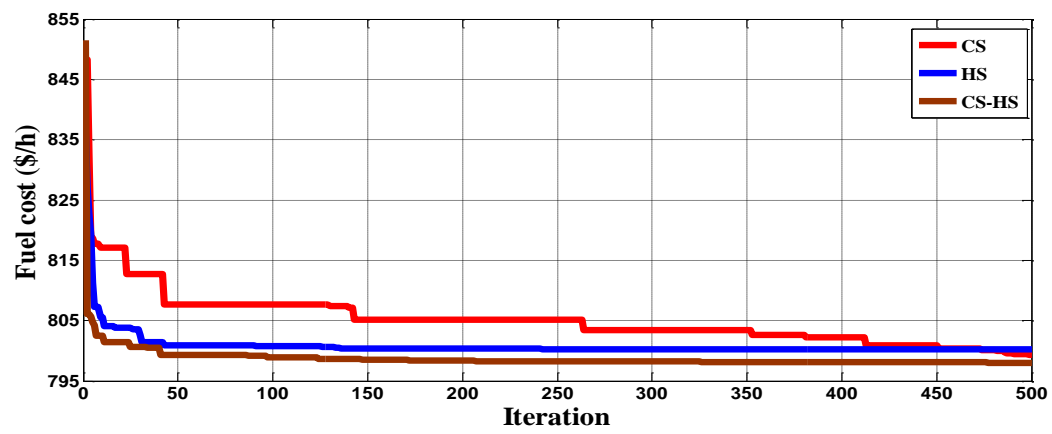

Figure 5a. Objective function curve for CASE 4

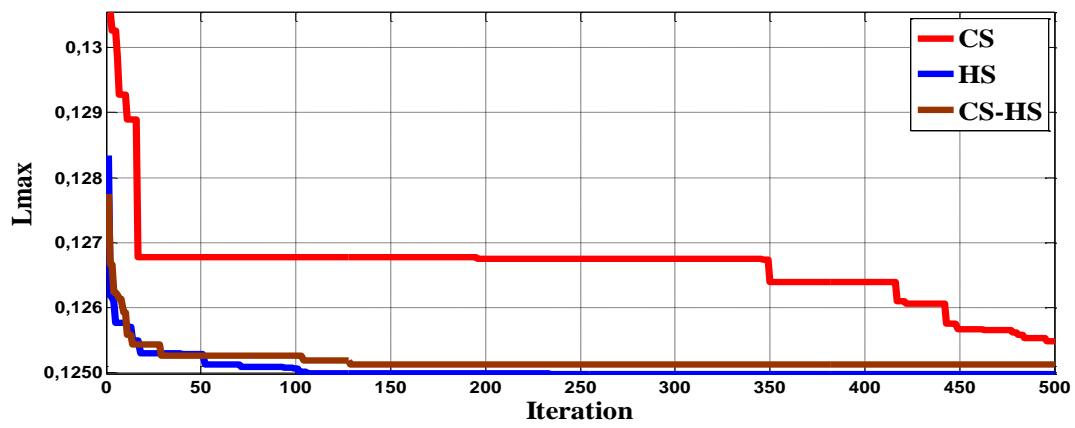

Figure 5b. Objective function curve for CASE 4

Case 4: Minimization of fuel cost and enhancement of voltage stability

The prediction of voltage instability is a problem of paramount significance in power systems. In [32] Kessel and Glavitch have developed a voltage stability index named $L_{\max }$ which is defined build on local indicators $L_{j}$ and it is presented by [32]:

$$
L_{\max }=\max \left(L_{j}\right) \quad j=1,2, \ldots, N L
$$

where ${ }^{L_{j}}$ is the local indicator of bus $\mathrm{j}$ and it is given as follows: 
$L_{j}=\left|1-\sum_{i=1}^{N G} H_{L G_{j i}} \frac{V_{i}}{V_{j}}\right| \quad j=1,2, \ldots, N L$

where $H$ matrix is produced by the partial inversion of $Y_{b u s}$. More specifics can be given in [32]. The indicator $L_{\max }$ varies between 0 and 1 where the lower the indicator, the more the system stable. Thus, enhancing voltage stability can be obtained by the minimization of $L_{\max }$ of the complete system [21]. Hence, the objective function can be formulated as:

$J(x, u)=\left(\sum_{i=1}^{N G} a_{i}+b_{i} P_{G_{i}}+c_{i} P_{G_{i}}^{2}\right)+\lambda_{L_{\max }}\left(L_{\max }\right)$

where $\lambda_{L_{\max }}$ is a weighting factor chosen as 100 in this work. The results of the optimization study are presented in Table 3 while the direction of convergence is appearing in Fig. 5. It seems that the ${ }^{L_{\max }}$ has been decreased from 0.1283 to 0.1251 compared with CASE 1 . Hence the results obtained are compared with other algorithms as given in table 4 .

Case 5: Minimization of emission

Electrical power generation from conventional sources of energy emits hazardous gases into the environment. The quantity of sulfur oxides SOx and nitrogen oxides NOx emission in tones per $\mathrm{hr}(\mathrm{t} / \mathrm{h})$ is higher with rise in generated power (in p.u) next the relationship presented in equation (27).The objective of OPF is to minimize emission :

$f(x, u)=$ Emission $=\sum_{i=1}^{N B}\left[\left(\alpha_{i}+\beta_{i} P_{G_{i}}+\gamma_{i} P_{G_{i}}^{2}\right) \times 0.001+\omega_{i} e^{\left(\mu_{i} P_{G_{i}}\right)}\right]$

where, $\alpha_{i}, \beta_{i}, \gamma_{i}, \omega_{i}$ and $\mu_{i}$ are all emission coefficients provided in [20]

The results yielded after optimization applied the CSHS technique are presented in Table 5 and the trend of optimization is shown in Fig.5a and 5b. The results appear that the emission has been decreased from $(0.3662 \mathrm{ton} / \mathrm{h})$ to ( $0.20476 \mathrm{ton} / \mathrm{h})$, Thus, the results obtained are compared with other techniques as shown in table 6.

Case 6: Minimization of real power loss

In this case, the purpose of the OPF problem is to minimize power losses; the real power loss to be minimized is formulated as follows:

$f(x, u)=P_{l o s s}=\sum_{i=1}^{n l} \sum_{j=1, j \neq i}^{n l} G_{i j}\left[V_{i}^{2}+V_{j}^{2}-2 V_{i} V_{j} \cos \left(\delta_{i j}\right)\right]$

where, $\delta_{i j}=\delta_{i}-\delta_{j}$ is the difference in voltage angles between bus $i$ and bus $j$ and $G_{i j}$ is transfer conductance.

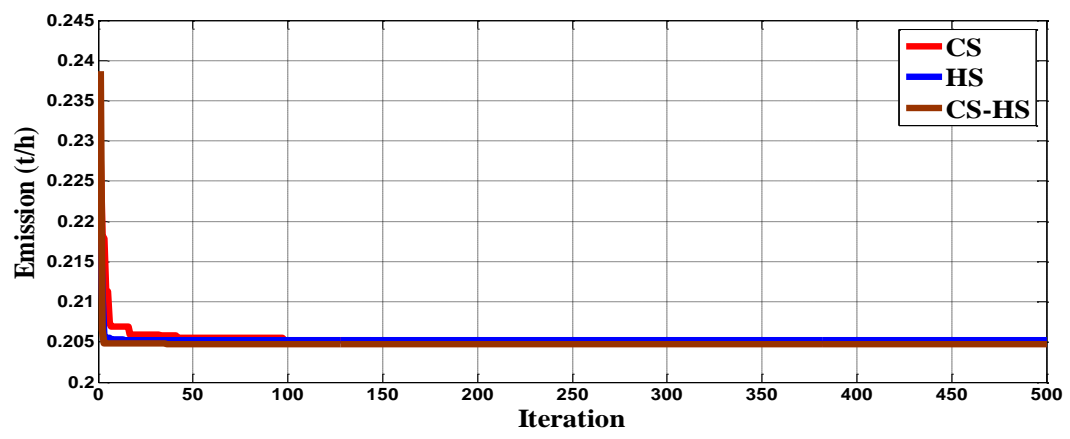

Figure 6. Objective function curve for CASE 5

Table 5. Optimum control variables for case 5 and case 6

\begin{tabular}{|c|c|c|c|c|c|c|}
\hline \multicolumn{4}{|c|}{ Case 5} & \multicolumn{3}{|c|}{ Case 6} \\
\hline Control variable & CS-HS & $\mathrm{CS}$ & HS & CS-HS & $\mathrm{CS}$ & $\mathrm{H}$ \\
\hline $\mathrm{P}_{\mathrm{G} 1}(\mathrm{MW})$ & 63.5637 & 64.1721 & 64.5007 & 51.6524 & 51.6568 & 51.6718 \\
\hline $\mathrm{P}_{\mathrm{G} 2}(\mathrm{MW})$ & 67.8700 & 67.3812 & 67.8834 & 79.6278 & 79.7125 & 80.0000 \\
\hline $\mathrm{P}_{\mathrm{G} 5}(\mathrm{MW})$ & 50.0000 & 49.9997 & 50.0000 & 50.0000 & 49.9973 & 50.0000 \\
\hline $\mathrm{P}_{\mathrm{G} 8}(\mathrm{MW})$ & 35.0000 & 35.0000 & 35.0000 & 35.0000 & 34.9675 & 35.0000 \\
\hline $\mathrm{P}_{\mathrm{G} 11}(\mathrm{MW})$ & 30.0000 & 30.0000 & 30.0000 & 30.0000 & 29.9796 & 30.0000 \\
\hline $\mathrm{P}_{\mathrm{G} 13}(\mathrm{MW})$ & 40.0000 & 40.0000 & 40.0000 & 40.0000 & 40.0000 & 40.0000 \\
\hline $\mathrm{V}_{1}(\mathrm{p} . \mathrm{u})$ & 1.1000 & 1.1000 & 1.1000 & 1.1000 & 1.1000 & 1.1000 \\
\hline $\mathrm{V}_{2}(\mathrm{p} . \mathrm{u})$ & 1.0933 & 1.0983 & 1.0781 & 1.0988 & 1.0972 & 1.1000 \\
\hline $\mathrm{V}_{5}(\mathrm{p} . \mathrm{u})$ & 1.0740 & 1.0835 & 1.0440 & 1.0809 & 1.0791 & 1.0814 \\
\hline $\mathrm{V}_{8}(\mathrm{p} . \mathrm{u})$ & 1.0854 & 1.0865 & 1.0384 & 1.0897 & 1.0862 & 1.0899 \\
\hline $\mathrm{V}_{11}(\mathrm{p} . \mathrm{u})$ & 1.1000 & 1.0681 & 1.1000 & 1.0987 & 1.1000 & 0.9000 \\
\hline $\mathrm{V}_{13}(\mathrm{p} . \mathrm{u})$ & 1.0965 & 1.0899 & 1.0392 & 1.0993 & 1.0993 & 1.1000 \\
\hline Qc10(Mvar) & 0.2013 & 0.2011 & 5.0000 & 0.2025 & 1.2314 & 5.0000 \\
\hline Qc12(Mvar) & 4.7013 & 2.1988 & 0 & 1.5592 & 4.4911 & 0 \\
\hline $\mathrm{Qc}_{15}$ (Mvar) & 2.4433 & 0.0063 & 5.0000 & 4.6077 & 0.1175 & 5.0000 \\
\hline Qc17(Mvar) & 4.9988 & 0.0482 & 0 & 1.8248 & 4.5130 & 0 \\
\hline $\mathrm{Qc}_{20}$ (Mvar) & 5.0000 & 3.7074 & 5.0000 & 4.2253 & 0.0156 & 0 \\
\hline $\mathrm{Qc}_{21}$ (Mvar) & 0.4902 & 0.0803 & 5.0000 & 4.9905 & 3.0702 & 5.0000 \\
\hline $\begin{array}{l}\text { Qc } 23 \text { (Mvar) } \\
5.0000\end{array}$ & 0.0401 & 2.4641 & 5.0000 & 0.2170 & 2.0676 & \\
\hline
\end{tabular}




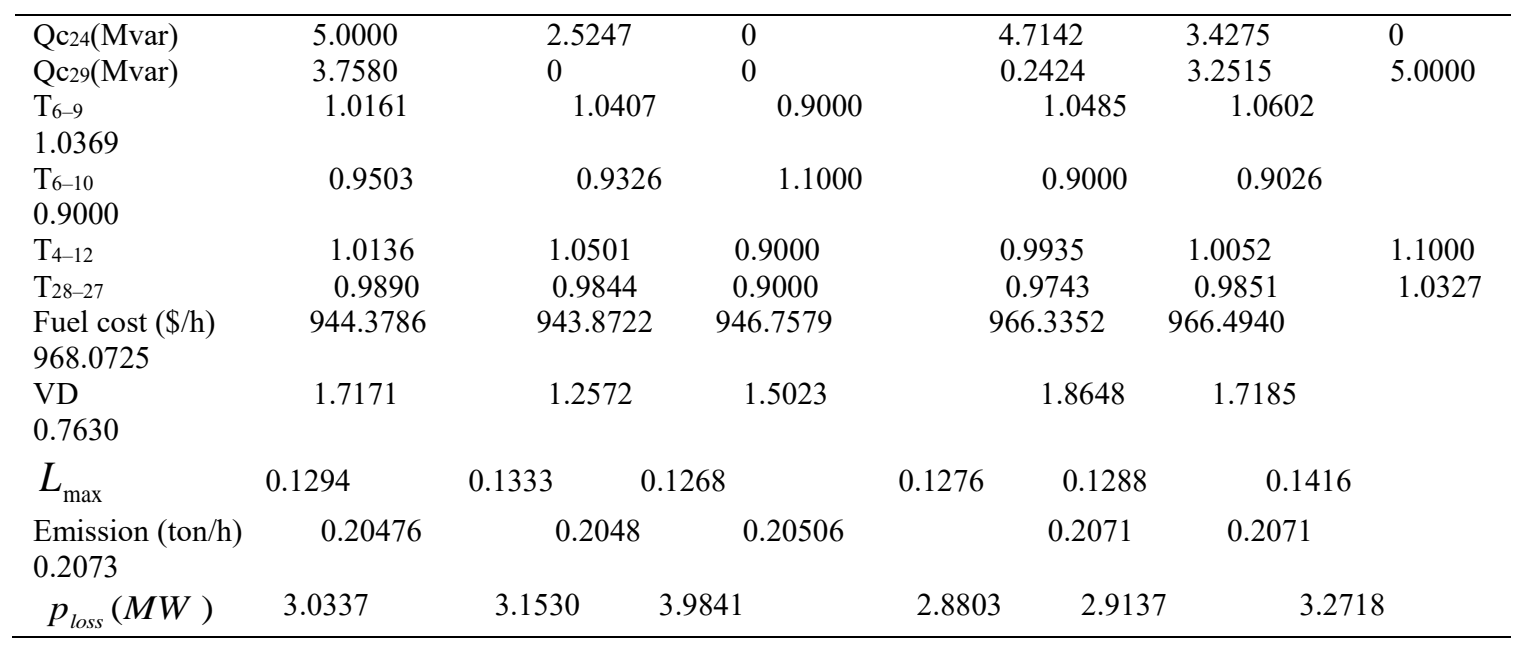

Table 6. Comparison of results for case 5 and case 6

\begin{tabular}{llll}
\hline \multicolumn{1}{c}{ Case 5 } & & \multicolumn{2}{c}{ Case 6 } \\
\hline Algorithms & Emission (ton/h) & Algorithms & $p_{\text {loss }}(M W)$ \\
\hline CS-HS & 0.20476 & CS-HS & 2.8803 \\
CS & 0.2048 & CS & 2.9137 \\
HS & 0.20506 & HS & 3.2 \\
MSA [29] & 0.20482 & MSA [29] & 3.1005 \\
ARCBBO [27] & 0.2048 & ARCBBO [27] & 3.1009 \\
GBICA [30] & 0.2049 & GWO [31] & 3.41 \\
\hline
\end{tabular}

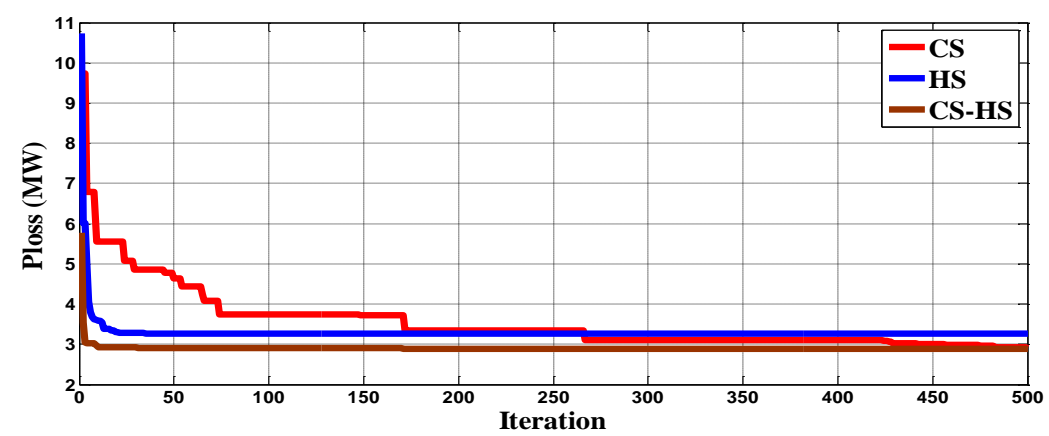

Figure 7. Objective function curve for CASE6

The tendency to decrease the objective function of total real power transmission loss using the CSHS technique appears Fig. 6. The optimal settings of the control variables are presented in Table 5 . In this case 6 by CSHS result in real power losses of $2.8803 \mathrm{MW}$, better than all the results summarized in the table 6 .

\subsection{IEEE 57-bus test system}

In order to exam the scalability of the suggested CSHS technique, a greater test system is taken into account in this article, which is the IEEE 57-bus test system. General system data of 57-bus system are given in [33].

Case 7: Minimization of fuel cost

The goal of this case is to minimize the total generating fuel cost. Hence, the objective function of this case is presented by (18). The CSHS is run so as to find the optimal settings for this case and the gained results are presented in Table 7 . The cost yielded for case 7 is $(41662.1893 \$ / \mathrm{h})$.

Table 7. Optimum control variables for case 7 and case 8

\begin{tabular}{lllllll}
\hline & \multicolumn{2}{c}{ Case 7 } & & \multicolumn{3}{c}{ Case 8 } \\
Control variable & CSHS & CS & HS & CSHS & CS & HS \\
\hline $\mathrm{P}_{\mathrm{G} 1}(\mathrm{MW})$ & 143.4303 & 144.8666 & 146.1972 & 141.7495 & 144.4274 & 149.8891 \\
$\mathrm{P}_{\mathrm{G} 2}(\mathrm{MW})$ & 91.8816 & 98.2138 & 100.0000 & 93.7131 & 92.3616 & 30.0000 \\
$\mathrm{P}_{\mathrm{G} 3}(\mathrm{MW})$ & 44.1534 & 46.1776 & 40.0000 & 45.7062 & 49.7799 & 46.8293 \\
$\mathrm{P}_{\mathrm{G} 6}(\mathrm{MW})$ & 75.3572 & 92.8569 & 30.0000 & 78.4672 & 53.5758 & 100.0000 \\
$\mathrm{P}_{\mathrm{G} 8}(\mathrm{MW})$ & 454.2645 & 470.7293 & 481.7175 & 457.3292 & 468.2286 & 469.4624 \\
$\mathrm{P}_{\mathrm{G} 9}(\mathrm{MW})$ & 96.6199 & 47.3525 & 100.0000 & 88.3416 & 93.9470 & 100.0000 \\
$\mathrm{P}_{\mathrm{G} 12}(\mathrm{MW})$ & 359.6901 & 366.0283 & 369.1071 & 361.2573 & 364.2777 & 370.5929 \\
$\mathrm{~V}_{1}$ (p.u) & 1.0661 & 1.0726 & 1.0737 & 1.0231 & 1.0211 & 1.1000 \\
\hline
\end{tabular}




\begin{tabular}{|c|c|c|c|c|c|c|}
\hline $\mathrm{V}_{2}$ (p.u) & 1.0678 & 1.0764 & 1.0791 & 1.0275 & 1.0240 & 1.1000 \\
\hline $\mathrm{V}_{3}(\mathrm{p} . \mathrm{u})$ & 1.0592 & 1.0645 & 1.0619 & 1.0160 & 1.0120 & 1.1000 \\
\hline $\mathrm{V}_{6}(\mathrm{p} . \mathrm{u})$ & 1.0636 & 1.0651 & 1.0650 & 1.0257 & 1.0167 & 1.1000 \\
\hline $\mathrm{V}_{8}(\mathrm{p} . \mathrm{u})$ & 1.0750 & 1.0769 & 1.1000 & 1.0457 & 1.0439 & 1.1000 \\
\hline $\mathrm{V}_{9}(\mathrm{p} . \mathrm{u})$ & 1.0685 & 1.0675 & 1.0820 & 1.0282 & 1.0265 & 1.1000 \\
\hline $\mathrm{V}_{12}(\mathrm{p} . \mathrm{u})$ & 1.0535 & 1.0572 & 1.0610 & 1.0072 & 1.0068 & 1.1000 \\
\hline $\mathrm{Qc}_{18(\mathrm{Mvar})}$ & 16.1246 & 0.1068 & 0 & 2.2705 & 0.3491 & 0 \\
\hline $\mathrm{Qc}_{25}$ (Mvar) & 15.2245 & 7.5240 & 16.5705 & 9.6667 & 6.8679 & 20.0000 \\
\hline $\mathrm{Qc}_{53}$ (Mvar) & 12.9365 & 6.7123 & 13.2102 & 16.1261 & 6.3440 & 20.0000 \\
\hline $\mathrm{T}_{4-18}$ & 1.1000 & 0.9063 & 1.1000 & 0.9652 & 0.9303 & 1.1000 \\
\hline $\mathrm{T}_{4-18}$ & 0.9941 & 1.0575 & 1.1000 & 0.9981 & 0.9886 & 1.0079 \\
\hline $\mathrm{T}_{21-20}$ & 1.0041 & 1.0133 & 0.9000 & 0.9790 & 0.9882 & 0.9839 \\
\hline $\mathrm{T}_{24-25}$ & 1.0188 & 0.9016 & 1.1000 & 0.9781 & 0.9576 & 1.1000 \\
\hline $\mathrm{T}_{24-25}$ & 0.9954 & 1.0332 & 0.9000 & 0.9511 & 0.9586 & 1.0002 \\
\hline $\mathrm{T}_{24-26}$ & 1.0166 & 1.0179 & 0.9931 & 1.0136 & 1.0258 & 1.0019 \\
\hline $\mathrm{T}_{7-29}$ & 1.0083 & 0.9943 & 1.0164 & 0.9985 & 0.9757 & 1.1000 \\
\hline $\mathrm{T}_{34-32}$ & 0.9631 & 0.9398 & 0.9000 & 0.9399 & 0.9344 & 0.9235 \\
\hline $\mathrm{T}_{11-41}$ & 0.9102 & 0.9547 & 0.9000 & 0.9000 & 0.9000 & 0.9000 \\
\hline $\mathrm{T}_{15-45}$ & 0.9843 & 0.9884 & 1.0017 & 0.9475 & 0.9525 & 1.0326 \\
\hline $\mathrm{T}_{14-46}$ & 0.9818 & 0.9854 & 1.0072 & 0.9534 & 0.9503 & 1.0330 \\
\hline $\mathrm{T}_{10-51}$ & 0.9934 & 0.9916 & 1.1000 & 0.9842 & 0.9767 & 1.0716 \\
\hline $\mathrm{T}_{13-49}$ & 0.9530 & 0.9519 & 0.9700 & 0.9218 & 0.9215 & 0.9939 \\
\hline $\mathrm{T}_{11-43}$ & 1.0047 & 0.9853 & 1.0992 & 0.9447 & 0.9429 & 1.1000 \\
\hline $\mathrm{T}_{40-56}$ & 0.9826 & 0.9640 & 0.9000 & 1.0448 & 1.0297 & 0.9000 \\
\hline $\mathrm{T}_{39-57}$ & 1.0279 & 0.9418 & 0.9000 & 0.9399 & 0.9467 & 1.1000 \\
\hline $\mathrm{T}_{9-55}$ & 1.0268 & 1.0084 & 1.0259 & 1.0180 & 0.9961 & 1.0704 \\
\hline Fuel cost $(\$ / h)$ & 41662.1893 & 41705.2382 & 41759.1345 & 41707.8925 & 41722.2262 & 41763.6339 \\
\hline VD & 1.4928 & 1.5546 & 1.6527 & 0.6947 & 0.7111 & 1.4651 \\
\hline$L_{\max }$ & 0.2807 & 0.2796 & 0.2889 & 0.2919 & 0.2914 & 0.2940 \\
\hline Emission (ton $/ \mathrm{h}$ ) & 1.3331 & 1.4129 & 1.4620 & 1.3442 & 1.3893 & 1.4311 \\
\hline$p_{\text {loss }}(M W)$ & 14.5973 & 15.4253 & 16.2232 & 15.7641 & 15.7980 & 15.9804 \\
\hline
\end{tabular}

Table 8. Comparison of the results obtained for Case 7 and Case 8

\begin{tabular}{ccccc}
\hline \multicolumn{2}{c}{ Case 7 } & \multicolumn{1}{c}{ Case 8 } & VD (p.u) \\
\hline Algorithms & Fuel cost $(\$ / \mathrm{h})$ & Algorithms & Fuel cost $(\$ / \mathrm{h})$ & 0.6947 \\
CSHS & 41662.1893 & CSHS & 41707.8925 & 0.7111 \\
CS & 41705.2382 & CS & 41722.2262 & 1.4651 \\
HS & 41759.1345 & HS & 41763.6339 & 0.67818 \\
MSA [29] & 41673.7231 & MSA [29] & 41714.9851 & 0.69723 \\
ICBO [25] & 41697.3324 & FPA [29] & 41726.3758 & \\
\hline
\end{tabular}

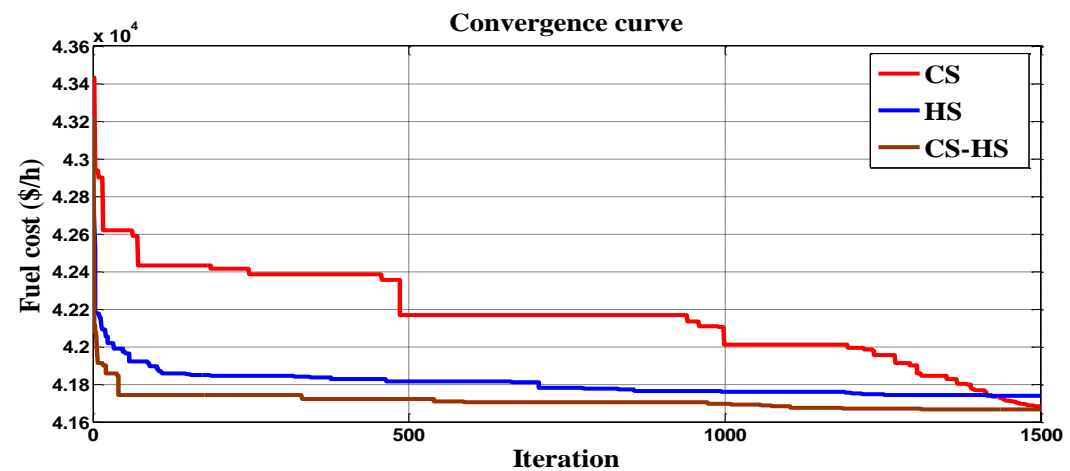

Figure 8. Objective function curve for CASE 7

Case 8: Minimization of fuel cost and voltage deviation

The purpose of the objective function is to minimize simultaneously both fuel cost and voltage deviation. The converted single objective function next equation (21) with weight factor $w$ is chosen as 100, the results of such optimization using the suggested CSHS technique are shown in Table 7. This table shows that the VD has been decrease from (1.4928 p.u.) to (0.6947 p.u.) compared with CASE 7. Hence, the cost has slightly augmented from (41662.1893 \$/h) to $(41707.8925 \$ / \mathrm{h})$ compared with CASE 7.

\section{CONCLUSION}

In this paper, a hybrid (CSHS) approach has been proposed as a new solution to solve the OPF problem. At first, in power systems, the OPF problem was reported as a nonlinear optimization problem with equality and inequality constraints. Where several objective functions have been considered to minimize the fuel cost, to improve the voltage profile, and to enhance the voltage stability in normal conditions. In addition, non-smooth cost objective function 
has been considered. The feasibility of the proposed CSHS method for solving OPF problems is demonstrated by using standard IEEE 30-bus and IEEE 57-bus test power systems. The proposed method does always promise most optimal solution and fast convergence. The simulation results demonstrate the effectiveness and robustness of the proposed algorithm to solve OPF problem in small and large test systems. Furthermore, the proposed algorithms in this study perform noticeably better than many other equivalent optimization methods in finding solutions of OPF. Reduction in hourly operation cost has been established almost in all the cases studied under the scope of this literature.

\section{REFERENCES}

[1] Cain M, O’Neill R, Castillo A. (2012). History of optimal power flow and formulations. FERC Staff Tech Pap, pp. 1-36.

[2] Hinojosa VH, Araya R. (2013). Modeling a mixedinteger-binary small-population evolutionary particle swarm algorithm for solving the optimal power flow problem in electric power systems. Appl. Soft Comput. J 13: $3839-3852$ https://doi.org/10.1016/j.asoc.2013.05.005

[3] Ghasemi M, Ghavidel S, Akbari E, Vahed AA. (2014). Solving non-linear, non-smooth and non-convex optimal power flow problems using chaotic invasive weed optimization algorithms based on chaos. Energy 73: 340-353.

https://doi.org/10.1016/j.energy.2014.06.026

[4] Abaali H, Lamchich MT, Raoufi M. (2007). Average current mode to control the three phase shunt active power filters under distorted and unbalanced Voltage conditions. AMSE Journals, Series 2A 80(2): 68-81.

[5] Ambriz-Perez H, Acha E, Fuerte-Esquivel CR, De La Torre A. (1998). Incorporation of a UPFC model in an optimal power flow using Newton's method. IEEE Proc Gener Transm Distrib 145: 336e44. https://doi.org/10.1049/ip-gtd:19981944

[6] Yan X, Quintana VH. (1999). Improving an interiorpoint-based OPF by dynamic adjustments of step sizes and tolerances. IEEE Trans. Power Syst 14: 709-717. https://doi.org/10.1109/59.761902

[7] Al-Muhawesh TA, Qamber IS. (2008). The established megawatt linear programming-based optimal power flow model applied to the real power 56-bus system in eastern province of Saudi Arabia. Energy 33: 12-21.

[8] Frank S, Steponavice I. (2012). Optimal power flow: A bibliographic survey I. Formulations and Deterministic Methods 3(3): 221-58.

[9] Chettih S, Khiat M, Chaker A. (2009). Var-voltage control by particle swarm optimization (PSO) methodapplication in the western algerian transmission system. AMSE Journals, Series Modeling A 82(2): 65-79.

[10] Ben Attous D, Labb Y. (2010). Particle swarm optimisation based optimal power flow for units with non-smooth fuel cost functions. AMSE Journals, Series Modelling A 83(3): 24-37.

[11] Benhamida F, Bendaoud A. (2009). A new formulation of dynamic economic dispatch using a hopfield neural network. AMSE Journals, Series Modelling A 82(2): $33-47$.
[12] Bentouati B, Chettih S, El Sehiemy RA, Wang GG. (2017). Elephant herding optimization for solving nonconvex optimal power flow problem. Journal of Electrical and Electronics Engineering 10(1): 1-6.

[13] Bentouati B et al. (2016). Optimal power flow using the moth flam optimizer: A case study of the algerian power system. TELKOMINIKA (1): 3. http://doi.org/10.11591/ijeecs.v1.i3.pp431-445

[14] Bhattacharya A, Chattopadhyay P. (2011). Application of bio-geography-based optimization to solve different optimal power flow problems. IET Gener Transm Distrib 5(1): 70. https://doi.org/10.1049/ietgtd.2010.0237

[15] Abaci K, Yamacli V. (2016). Differential search algorithm for solving multi-objective optimal power flow problem. Int. J. Electr. Power Energy Syst. 79: 110. https://doi.org/10.1016/j.ijepes.2015.12.021

[16] Bentouati B, et al. (2016). A solution to the optimal power flow using multi-verse optimizer. J. Electrical Systems 12-4 pp. 716-733,

[17] Roy PK, Paul C. (2015). Optimal power flow using krill herd algorithm. Int. Trans. Electr. Energy Syst 25(8): 1397-1419. https://doi.org/10.1002/etep.1888

[18] Deb XYS. (2013). Cuckoo search: recent advances and applications. https://doi.org/10.1007/s00521-013-13671

[19] Geem ZW, Kim JH, Logan than GV. (2001). A new heuristic optimization algorithm: Harmony search. Simulation 76(2): 60-68. https://doi.org/10.1177/003754970107600201

[20] Chaib AE, Bouchekara HREH, Mehasni R, Abido MA. (2016). Optimal power flow with emission and nonsmooth cost functions using backtracking search optimization algorithm. International Journal of Electrical Power \& Energy Systems 81: 64-77.

[21] Abou El Ela AA, Abido MA. (2010). Optimal power flow using differential evolution algorithm. Electr. Power Syst. Res 80 (7): 878-885.

[22] Duman S. (2016). Symbiotic organisms search algorithm for optimal power flow problem based on valve-point effect and prohibited zones. Neural Comput. Appl. 28(11): 3571-3585.

[23] Niknam T, Narimani MR, Jabbari M, Malekpour AR. (2011). A modified shuffle frog leaping algorithm for multi-objective optimal power flow. Energy 36(11): 6420-32. https://doi.org/10.1016/j.energy.2011.09.027

[24] Niknam T, Narimani MR, Azizipanah-Abarghooee R. (2012). A new hybrid algorithm for optimal power flow considering prohibited zones and valve point effect. Energy Convers. Manage 58: 197-206.

[25] Bouchekara HREH, Chaib AE, Abido MA, El-Sehiemy RA. (2016). Optimal power flow using an Improved Colliding Bodies Optimization algorithm. Applied Soft Computing 42: 119-131.

[26] Mahdad B, Srairi K. (2016). Security constrained optimal power flow solution using new adaptive partitioning flower pollination algorithm. Applied Soft Computing 46: 501-522.

[27] Ramesh Kumar A, Premalatha L. (2015). Optimal power flow for a deregulated power system using adaptive real coded biogeography-based optimization. Electrical Power and Energy Systems 73: 393-399. https://doi.org/10.1016/j.ijepes.2015.05.011 
[28] Roy R, Jadhav HT. (2015). Optimal power flow solution of power system incorporating stochastic wind power using Gbest guided artificial bee colony algorithm. Electrical Power and Energy Systems 64: 562-578.

[29] Mohamed AAA, Mohamed YS, El-Gaafary AAM, Hemeida AM. (2017). Optimal power flow using moth swarm algorithm. Electric Power Systems Research 142: 190-206.

[30] Ghasemi M, Ghavidel S, Ghanbarian M. (2015). Multiobjective optimal electric power planning in the power system using Gaussian bare-bones imperialist competitive algorithm. Information Sciences. 294: 286304. https://doi.org/10.1016/j.ins.2014.09.051

[31] El-Fergany AA, Hasanien HM. (2015). Single and multi-objective optimal power flow using grey wolf optimizer and differential evolution algorithms. Electric Power Components and Systems 43: 1548-1559. https://doi.org/10.1080/15325008.2015.1041625

[32] Kessel P, Glavitsch H. (1986). Estimating the voltage stability of a power system. IEEE Trans Power Deliv 1: 346-54. https://doi.org/10.1109/TPWRD.1986.4308013

[33] Zimmerman RD, Murillo-Sánchez CE, Thomas RJ. Matpower http://www.pserc.cornell.edu/matpower

\section{NOMENCLATURE}

$\mathrm{J}(x, u) \quad$ Objective function.

$\mathrm{h}(\mathrm{x}, \mathrm{u}) \quad$ Set of equality constraints.

$\mathrm{g}(\mathrm{x}, \mathrm{u}) \quad$ Set of inequality constraints.

$\mathrm{X} \quad$ State variables' Vector.
U Control variables' Vector.

PG Active power bus generator.

VG Voltage magnitude at $i$-th PV bus (generator bus).

T Transformer tap setting.

QC Shunt VAR compensation.

PG1 Generator active power at slack bus.

VL Bus voltage of $p$-th load bus (PQ bus).

QG Reactive power generation of all generator units.

SL Transmission line loading (or line flow).

$\mathrm{NL}$ and $\mathrm{nl} \quad$ Number of load buses and the number of transmission lines.

NC, NT Number of VAR compensators, the number and NG of regulating transformers and the number of generators respectively.

$P_{D} \quad$ Active and reactive load demands.

$Q_{D}$

$G_{i j} \quad$ Transfer conductance

$B_{i j} \quad$ Susceptance between bus $i$ and bus $j$, respectively.

$V_{L_{p}}^{\min }$ and

$V_{L_{p}}^{\max }$

Lowest and upper load voltage of ith unit.

$S_{l_{q}}$

$S_{l}^{\max }$

Apparent power flow of ith branch.

Maximum apparent power flow limit of ith branch. 